Politisches Denken · Jahrbuch 1993 
In Verbindung mit der

Deutschen Gesellschaft zur Erforschung des Politischen Denkens.

Redaktionsanschriften:

Prof. Dr. Volker Gerhardt, Institut für Philosophie, Humboldt Universität Berlin, Unter den Linden 6, 10099 Berlin

Prof. Dr. Henning Ottmann

Philosophisches Seminar der Universität Basel,

Nadelberg 6-8, CH-4051 Basel

Wissenschaftlicher Beirat:

Karl Dietrich Bracher (Bonn), Reinhard Brandt (Marburg), Maurice Cranston (London), John Dunn (Cambridge), Iring Fetscher (Frankfurt), Klaus Hartmann (Tübingen) ( $\dagger$ ), Wilhelm Hennis (Freiburg), Dieter Henrich (München), Otfried Höffe (Tübingen), Hasso Hofmann (Berlin), Nikolaus Lobkowicz (Eichstätt), Hermann Lübbe (Zürich), Odo Marquard (Gießen), Kenneth Minogue (London), Michael Oakeshott (London) ( $\dagger$ ), J. G. A. Pocock (Hopkins University), Melvin Richter (New York), Quentin Skinner (Cambridge), Michael Stolleis (Frankfurt) 


\title{
Politisches Denken Jahrbuch 1993
}

\author{
Herausgegeben von \\ Volker Gerhardt, Henning Ottmann \\ und Martyn P. Thompson
}

Verlag J. B. Metzler

Stuttgart - Weimar 
Die Deutsche Bibliothek - CIP-Einheitsaufnahme

Politisches Denken: Jahrbuch ...;

Jahrbuch der Deutschen Gesellschaft zur Erforschung des Politischen Denkens. Stuttgart: Metzler.

Erscheint jährlich. - Aufnahme nach 1991 (1992)

ISSN 0942-2307

1991 (1992) -

Dieses Werk einschließlich aller seiner Teile ist urheberrechtlich geschützt. Jede Verwertung außerhalb der engen Grenzen des Urheberrechtsgesetzes ist ohne Zustimmung des Verlages unzulässig und strafbar.

Das gilt insbesondere für Vervielfältigungen, Übersetzungen,

Mikroverfilmungen und die Einspeicherung und Verarbeitung in elektronischen Systemen.

ISSN $0942-2307$

ISBN 978-3-476-00954-8

ISBN 978-3-476-03503-5 (eBook)

DOI 10.1007/978-3-476-03503-5

(C) 1993 Springer-Verlag GmbH Deutschland

Ursprünglich erschienen bei J. B. Metzlersche Verlagsbuchhandlung

und Carl Ernst Poeschel Verlag GmbH in Stuttgart 1993 


\title{
Inhalt
}

\author{
Aufsätze \\ PATRICK BAHNers \\ Vergangenheitsbewältigung bei Tacitus \\ 1 \\ Richard RorTy \\ Does Democracy need Foundations? \\ 21 \\ JoAchim Fest \\ Offene Gesellschaft mit offener Flanke
}

25

Benjamin R. BARber

Foundationalism and Democracy

29

\section{Amy Gutmann}

Democracy and Philosophy:

Does Democracy need Foundations?

39

Hans BuchHeIM

Zu Hobbes' "Leviathan“

47

\section{Dietmar Herz}

Das Leben des Thomas Hobbes aus Malmesbury, in Versen geschrieben im Jahre 1672

59

Richard SaAge

Zum Begriff der Utopie und des

Konservatismus bei Karl Mannheim 
GüNTER FIGAL

Der Intensitätsgrad des Politischen.

Überlegungen im Anschluß an Carl Schmitt

105

\author{
Ulrich K. Preuß \\ Vater der Verfassungsväter? \\ Carl Schmitts Verfassungslehre und die \\ verfassungspolitische Diskussion der Gegenwart \\ 117 \\ Peter J. Opitz \\ Erste Spurensicherungen: \\ Zur Genesis und Gestalt von Eric Voegelins \\ "History of Political Ideas " \\ 135 \\ Heinz Kleger \\ Rückkehr der Bürgergesellschaft? \\ Überlegungen zur politischen Philosophie \\ 157
}

\title{
Diskussion
}

\section{Horst Firsching}

Anmerkungen zu einer

"Theorie der Politik als Gesellschaftstheorie"

173

\section{Rezensionen}

Jörg PANnier

Kommunitarismus für Anfänger

Über: Axel Honneth, Kommunitarismus.

Eine Debatte über die moralischen

Grundlagen moderner Gesellschaften

183 
ERnST VOLLRATH

Fragmente der Erfahrung des Politischen

Über: Hannah Arendt, Was ist Politik?

Fragmente aus dem Nachlaß

185

Uwe Justus Wenzel

Liberaler Glaube

Über: John Rawls, Die Idee des

politischen Liberalismus

189

Henning Ottmann

Ein Klassiker der Schmitt-Literatur

Über: Hasso Hoffmann, Legitimität

gegen Legalität. Der Weg der politischen

Philosophie Carl Schmitts

193

Christoph Quarch

Sokrates als Vater des

europäischen Rechtsdenkens.

Über: Gregory Vlastos, Socrates.

Ironist and moral philosopher.

195 